\title{
A complexidade da participação das crianças na educação infantil
}

Kátia Adair Agostinho*

\section{Resumo}

O presente estudo defende a participação e inclusão das crianças na creche e pré-escola para a produção de espaços de educaçáo democráticos que se contraponham à exclusão social e contribuam na produção e consolidação de uma sociedade de afirmação de direitos sociais. A participaçáo das crianças permanece em larga medida por se concretizar, sendo um desafio que precisa ser enfrentado, nas suas contradiçóes, impasses e paradoxos teóricos, sociais e políticos. Ao aprofundar a temática compreende-se sua complexidade teórica, e é sobre esta complexidade que este texto irá se deter. A discussão a respeito da participação das crianças para uma educaçáo democrática se cruza com um conjunto de conceitos importantes que precisam ser aprofundados, compreendidos e conectados, para que seja possível contar com os contributos geracionais na efetivação da educação aqui preconizada, que vençam modelos adultocêntricos e não pode prescindir da produçáo teórica de abordagens inclusivas. As crianças como sujeitos de conhecimento e produtoras de sentido têm "voz", são legítimas as formas de comunicação e relação que utilizam para se expressar e, ao fazê-lo, contribuem na renovação e reprodução dos contextos em que participam quando existe quem esteja interessado em ouvir suas vozes. É importante reconhecer as diferentes formas de participaçáo das crianças pequenas com base nos seus padróes culturais e nas suas práticas cotidianas, em questôes que lhes são significativas e lhes dizem respeito.

Palavras-chave: Infância. Educação Infantil. Direitos da Criança.

* Doutora em Estudos da Criança pela Universidade do Minho, Portugal. Professora do Departamento de Metodologia do Ensino do Centro de Educação da Universidade Federal de Santa Catarina (UFSC). 


\section{Introdução}

Os estudos mais recentes sobre o letramento chamam a atenção para a diversidade de práticas de uso da escrita das quais participamos em nossa vida social. Cada prática, dependendo do objetivo, do domínio e da cultura em que está inserida desenvolve-se de modo particular.

O letramento literário, compreendido como o conjunto de práticas sociais que usa a escrita ficcional, pode se configurar de modo mais informal ou seguir procedimentos específicos da leitura literária crítica, normalmente, realizada em ambiente acadêmico. Este tipo de letramento oferece ao aluno uma leitura mais especializada e diferente da realizada em seu cotidiano: "[...] letramento literário exige o contato frequente e adequado com obras literárias, abordadas literariamente, num nível muitas vezes sofisticado, no sentido amplo e complexo, de letramento, que nem sempre a escolarização dá conta" (PAULINO, 2010, p. 408).

Dados que apontam que a escola não está dando conta desse seu papel na sociedade brasileira são os resultados de avaliaçóes oficiais, como o do Sistema de Avaliação da Educação Básica (SAEB), que avalia os alunos do Ensino Fundamental, por meio da Prova Brasil. Esse indicador visa avaliar a qualidade do ensino oferecido pelo sistema educacional brasileiro a partir de testes padronizados e questionários socioeconômicos. Porém, os resultados dessa avaliação têm sido pouco satisfatórios, pois geralmente a média nacional fica abaixo da meta definida para a Prova. Nesse sentido, em termos de letramento, Magda Soares (2010, p. 63) afirma: "Eu diria que temos avaliado muito, e pesquisado pouco ou nada, sobre as causas e as circunstâncias que podem explicar os baixos resultados ou o fracasso das nossas crianças em leitura, os baixos níveis de letramento da população jovem e adulta”.

Considerando alguns fatores, tais como a lacuna nos estudos sobre letramento no Brasil, o frágil desempenho dos alunos na Prova de Língua Portuguesa da Prova Brasil e o alcance das avaliaçôes institucionais enquanto importantes vetores no universo escolar, o presente artigo objetiva analisar a Prova Brasil, que atinge um contingente de alunos representativo de todo o Ensino Fundamental no Brasil, a fim de observar como são propostas nela as atividades de leitura do texto ficcional, já que estas podem indicar náo só os modos de leitura ou as práticas de leitura literária presentes na prova como também o conceito de literatura constituinte dessa avaliação. 


\section{Letramento como prática social: o letramento literário na escola}

A construção e consolidação do espaço público de educação democrático e justo necessita da participaçáo das crianças pequenas. Ouvir as vozes das crianças - como se consagrou chamar nas discussôes sobre este tema - é colocar em prática a construção de uma sociedade de afirmação de direitos sociais, em contraposição à exclusão social, contando com o contributo geracional para pensar uma educaçáo inclusiva e que comporte as singularidades dos sujeitos que dela participam.

Ao me embrenhar no aprofundamento acerca da participação das crianças compreendi que para possibilitar a sua participação nos contextos de sua educação, precisamos, primeiro, reconhecer a complexidade da questáo. Há um emaranhado de conceitos que precisam ser explicitados, aprofundados e relacionados, percebendo os múltiplos sentidos que as terminologias empregadas nas discussôes podem assumir. Para este artigo, elegi tratar da concepção das crianças como atores sociais e sujeitos de direitos, da democracia comunicativa, dos direitos das crianças e neles o de participação (com a tensão intrínseca entre as ideias de proteção e participação) e de uma cidadania vivida, acolhendo seus pontos de vista expressados pelas diferentes vias de comunicação. Estes são conceitos fulcrais na orientação das práticas educativas participativas, reconhecendo que os mesmos não esgotam toda a complexidade da temática.

\section{Criança: atores sociais e sujeitos de direito}

O reconhecimento de que as crianças são atores sociais é central para a discussão aqui tecida. O desenvolvimento de teorias que percebem as crianças como atores sociais de direitos próprios, e não apenas como objetos de socialização, tem impulsionado as discussôes acerca da participação das crianças. Essa concepção é fundamental para o êxito da educação democrática e justa com a participação das crianças e é ampliada com as ideias de Manuela Ferreira (2010), quanto à necessidade de "uma dupla significação":

i) elas são seres humanos com poder de simbolização e reflexão, de tomadas de iniciativa para a acção e acçáo social, náo apenas activamente implicadas na construção das suas próprias vidas, mas também nas daqueles com quem se relacionam e que as rodeiam, e na da sociedade em que tomam parte, quando experimentam e aprendem a lidar com as possibilidades e os constrangimentos das estruturas sociais no quotidiano;

ii) enquanto seres humanos elas são intrinsecamente seres 
sociais que, sujeitas à socialização da cultura adulta a reproduzem, não obstante serem igualmente capazes de a reinterpretar consoante os seus interesses, desejos, entendimentos, lógicas, crenças e valores individuais e/ou colectivos e, através disso, de a reconfigurar em sistemas organizados geradores de culturas e ordens sociais infantis e, mais ainda, de convocar e gerir estrategicamente ambas as culturas de modos tấo variados quantos os interlocutores e as conjunturas que enfrentam. Sendo actores sociais auto e hetero-construídos no plano cognitivo e cultural, (re)produzem sentidos na/sobre a vida social cuja proliferação e manutenção com e ao lado de interacçóes intra e intergeracionais em contextos concretos influenciam as suas circunstâncias sociais de existência, são por elas influenciados e podem ainda instituir outras que alteram o próprio espaço social da infância. (FERREIRA, 2010, p. 156-157).

A compreensão das crianças como sujeitos de conhecimento e produtoras de sentido assume como legítimas as suas formas de comunicação e relação "como contributos a ter em conta na renovação e reforço dos laços sociais nas comunidades em que participam" (FERREIRA, 2010, p.157). As crianças têm "voz" porque têm opinióes, ideias, experiências, sentimentos a nos dizer. Importa, então, que queiramos ouvi-las.

Tal perspectiva se insere na educação com vistas à defesa da construção de uma educação com base nos valores da democracia e da justiça social, para que a pré-escola assim como a creche e a escola - se constitua lugar de exercício da cidadania plena, em que a participação de todos os envolvidos na relação pedagógica - profissionais, familiares e crianças - seja efetiva na construção do espaço público de educaçáo democrático e justo. Compreendendo que "a luta pela institucionalidade democrática é, no fundo, a luta pelo direito, [...] que incorpora e torna concretizáveis os valores de liberdade, da igualdade, da autonomia, da solidariedade, da subjectividade e da justiça social" (SANTOS, 1999, p. 8).

\section{Democracia, que democracia?}

Contemporaneamente, vivemos a tensão que atravessa hoje a dinâmica do avanço democrático, "fala-se em direitos quando menos existem os direitos; fala-se em democracia quanto mais ela nos falta" (KRAMER, 2003, p. 56). Um olhar sobre nosso entorno social confirma isso.

Os impactos do projeto neoliberal trazem profundas consequências para a sociedade global, com a emergência de um Estado mínimo, que se isenta 
progressivamente de seu papel de garantidor de direitos, que encolhe suas responsabilidades sociais e as transfere para a sociedade civil, que tem de ser ativa e propositiva, operando, assim, deslocamentos de sentido nas noçóes de democracia, cidadania e participação.

Apresenta-se, entáo, a difícil tarefa de decifrar essa aparente semelhança e seus possíveis deslizamentos semânticos e deslocamentos de sentido. Instaura-se uma disputa de significados para referências, exaltadas como propulsoras da transformação, cuja aparência está sólida e cuidadosamente construída com uma concepção minimalista de democracia, que restringe o espaço político participante e o campo de ação.

Desse modo, minha perspectiva é a mesma dos setores "que visam alargar os sentidos de comunidade e de inclusão, procurando acentuar os direitos e tornar visíveis as variadas exclusões que o Estado e suas políticas vão produzindo" (ARAÚJO, 2007, p. 84). Importa compreender que o aprofundamento da democracia e da cidadania, através da consolidação dos direitos políticos, econômicos e sociais e da concretização dos direitos culturais, está no centro da educação (SARMENTO, 2000), e as temáticas que a envolvem mantêm entre si uma ligação profunda.

Os estudos feministas de Iris Young (1997) e sua ideia da democracia e da participação como elementos-chave para a justiça corroboram com as defesas aqui apresentadas. A preocupação da autora, da qual partilho, está relacionada à importância que as experiências possam ter para uma produção de voz, em termos de uma ação intervencionista, para uma possível mudança social e, assim, proporcionar a construção da nova pólis e da justiça.

Sua ideia de democracia comunicativa atenta aos aspectos não linguísticos da comunicação, à ética do cuidado e da solidariedade para com o Outro, ao reconhecimento da diferença, preservando a pluralidade, à valorização da emoção e da sensibilidade, favorecendo uma visão mais completa da própria justiça. Este é um importante contributo, porque:

[...] reconhece que quando o diálogo político objetiva resolver os problemas coletivos, justamente exige uma pluralidade de perspectivas, estilos de falas e maneiras de expressar a particularidade da situação social, bem como a aplicabilidade dos princípios gerais. Uma teoria da discussão democrática útil para o mundo contemporâneo deve explicar a possibilidade de comunicação entre as diferenças de cultura e posição social. Tal teoria da democracia precisa de uma concepção ampla e plural de comunicaçáo que inclui tanto a expressão e a extensão de entendimentos comuns, caso existam, como o oferecimento e 
reconhecimento de significados compartilhados. (YOUNG, 1997, p. 73-74, tradução nossa).

Busca-se, então, não incorrer nos equívocos de beneficiar grupos ou pessoas com maiores privilégios simbólicos e materiais, de desviar dos posicionamentos contrários pela busca do consenso, de descuidar do fato de nem todos terem as mesmas condiçóes e nem utilizarem as mesmas vias de comunicação, podendo se expressar de vários modos.

Contrariando a norma de igualdade, fundada no escamoteamento e no esmorecimento da diferença, o propósito aqui é o respeito e a proteção da ação humana nas suas singularidades de geração, gênero, etnia, social, cultural, focando o caráter positivo das diferenças. Não basta o reconhecimento do direito às diferenças identitárias, "com essa tolerância neoliberal tão em voga, mas caberia intensificar as diferenciaçóes, incitá-las, criá-las, produzi-las" (PELBART, 1993, p. 23), em nossa sociedade cada dia mais codificada, que restringe e pasteuriza sua diversidade potencial.

\section{Criança tem direito, criança participa}

O reconhecimento das crianças como cidadãos por direito próprio é tardio (LANSDOWN, 2005). Tal fato se deve a concepçóes, calcadas na Psicologia do Desenvolvimento e na Sociologia de cariz durkheimiano, que náo reconhecem nas crianças as competências que os adultos consideram necessárias para o exercício da cidadania, associadas à idade, imaturidade, vulnerabilidade, entre outros aspectos. $\mathrm{O}$ desafio encontra-se justamente em superar esta visão, ouvir as crianças, conhecer seus pontos de vista para contar com o seu contributo na construção do espaço público democrático e justo na educação infantil.

As discussóes acerca dos direitos de participação das crianças pequenas se alinham com as que vêm sendo travadas nos estudos feministas e pós-coloniais. As políticas de reconhecimento têm construído entendimentos mais alargados e aprofundados de representação, diferença e identidade para o estabelecimento da justiça social, com noçóes mais cosmopolitas de cidadania, nos quais se implemente uma comunicaçáo democrática inclusiva, que aposte na interdependência como motor de força da construção de cidadania para vencer a relação dicotômica dependência/independência.

A ideia de interdependência humana (COCKBURN, 1998; LISTER, 2007), na qual crianças e adultos são mutuamente dependentes, sublinhando o reconhecimento de que as crianças não são idênticas aos adultos ou que elas devam desfrutar exatamente dos mesmos direitos civis e políticos, ajuda-nos a pensar a 
participação das crianças, no sentido de que alguns direitos devem ser compartilhados com os adultos, em forma de direitos humanos; alguns são específicos para crianças, sob a forma de direitos das crianças.

Adultos e crianças são reciprocamente dependentes, sendo as crianças claramente dependentes de outros. Entretanto, todos os membros da sociedade são dependentes das crianças para a continuação e o futuro da existência. Assim reconhecemos a interdependência social e o modo como os custos de reprodução da sociedade caem de forma irregular, sobre determinadas pessoas, em determinados momentos da sua trajetória de vida.

É necessário equilibrar o direito de proteção com o de participação, com respeito a essas duas dimensôes do direito das crianças que não são excludentes, para que elas estejam protegidas adequadamente, de acordo com as suas capacidades em crescimento, bem como respeitadas como cidadãos, como pessoas e como portadores de direitos.

A atual ambiguidade social que pesa sobre as crianças - de valorização e acento na sua proteção, com uma regulação cada vez maior, e, por outro lado, o estímulo para que sejam indivíduos autônomos - exacerba-se com o discurso da segurança na sociedade de risco, (JANS, 2004). Tal quadro nos coloca a importante tarefa de aprender a lidar com a ambivalência, ao invés de cancelá-la, mantendo-nos atentos a ela e compreendendo-a como um fenômeno social, evitando a inclinação para acentuar o controle unilateral.

Os Direitos das Crianças de Proteção, Provisão e Participação (SOARES, 2005) são interdependentes, constituindo-se condição da sua própria realização; porém, tradicionalmente, são enfatizados os direitos de Proteção e os de Provisão, enquanto que os de Participação têm recebido menos atenção, tanto nas políticas quanto nas práticas sociais. São também estes últimos que geram maior controvérsia (Art. 12 - a opinião das crianças; Art. 13 - a liberdade de expressão das crianças; Art.14 - liberdade de pensamento, consciência e religião; Art. 15-liberdade de associação).

No ocidente, essas discussōes foram impulsionadas com o Art. 12 da Convenção das Naçôes Unidas sobre os Direitos da Criança (UNICEF, 1989), os quais lhe proporcionam o direito de expressar seus pontos de vista sobre todos os assuntos que dizem respeito a ela e ter essas opiniôes tidas em conta. Tradicionalmente, as crianças eram excluídas dos direitos de primeira geração ou dos direitos de autonomia: liberdade de interferência e direito à integridade física e mental e de autodeterminação.

No Brasil, os direitos específicos das crianças aparecem na Constituição de 1988 (BRASI, 1988), com todo o movimento de abertura do país. Em 1990, temos o Estatuto da Criança e do Adolescente (ECA), fruto de intensa mobilização da sociedade 
civil brasileira, constituindo-se um instrumento de luta emancipatória em direção a uma relação mais democrática entre adultos e crianças (BRASIL, 1990). Com ele temos uma nova concepção de criança como "sujeito político" e "sujeito de direitos", considerando, assim, as crianças com status próprio de cidadáos, contrapondo-se ao, então, Código de Menores, que concebia a criança apenas como "menor carente, abandonado ou infrator".

No ECA, temos em seu Capítulo II -"do direito à liberdade, ao respeito e à dignidade", o Art. 15 no qual "a criança e o adolescente têm direito à liberdade, ao respeito e à dignidade como pessoas humanas em processo de desenvolvimento e como sujeitos de direitos civis, humanos e sociais garantidos na Constituição e nas leis" (BRASIL, 1990), e o seguinte do qual destacamos as alíneas que, por ora, nos interessam: "Art. 16 - O direito à liberdade compreende os seguintes aspectos: [...] II opinião e expressão; [...] V - participar da vida familiar e comunitária, sem discriminação; [...] VI - participar da vida política, na forma da lei” (BRASIL, 1990).

Como podemos perceber, o direito de expressar sua opinião e ter essa tomada em consideração, em qualquer assunto ou procedimento que afetam a criança, está consagrado na Convenção dos Direitos da Criança (UNICEF, 1989) e no ECA (BRASIL, 1990). Sabe-se, contudo, que a extensão e a forma como tal direito se traduz no exercício dos direitos de cidadania variam entre os diferentes contextos e concepçôes.

A temática dos direitos, embora consagrada em importantes produçôes teóricas, encontra na realidade vivenciada uma distância imensa entre teoria e discurso e sua tradução na prática. O Comitê das Naçóes Unidas, ao refletir sua preocupação acerca da problemática da efetivação desses direitos, sobre os Direitos da Criança (UNICEF, 1989), esclareceu o alcance do Art. 12, publicando um Comentário Geral no 7 (UNITED NATIONS, 2006). Nele a necessidade de respeitar as opiniốes e sentimentos, mesmo dos mais jovens, é enfatizada e os Estados que fazem parte são encorajados a tomar todas as medidas adequadas para assegurar que o conceito de criança, como titular de direitos com liberdade para expressar opinióes e de ser consultada sobre questôes que a afetem, seja posto em prática o mais cedo possível, a partir de formas adequadas às capacidades da criança, aos interesses e direitos à proteção de experiências nocivas (UNITED NATIONS, 2006).

A participação é uma variável em construção (PERCY-SMITH; THOMAS, 2010), temos que estar atentos aos cuidados semânticos que o termo exige, além de observar a necessária contextualização social e cultural em que ocorre. A produção de diferentes estudos tem cercado o assunto, admitindo as dificuldades ao abordar e aprofundar a temática da participação das crianças. Tudo isso se torna ainda mais 
desafiante quando as crianças são as pequenas, considerando que essa faixa etária não encontra acúmulo de estudos ainda, recaindo sobre elas, com maior rigor, os limites dos referenciais utilizados para crianças maiores e jovens, por não observarem as suas especificidades, sendo as crianças mais novas identificadas como um dos grupos que enfrentam as maiores barreiras para serem envolvidos.

\section{Cidadania vivida na creche e pré-escola}

Para as crianças, os direitos são específicos, são experiências e experimentaçóes, e não uma interpretação abstrata da Convençấo dos Direitos das Crianças e do ECA, em um currículo de cidadania (HILL et al., 2004). O foco sobre a cidadania das crianças reforça a necessidade de uma concepção dialética da mesma, que vai além de um conjunto de direitos e salienta o valor e a importância da ideia de "cidadania vivida". Os critérios para a inclusão de cidadãos não podem ser uniformes. Se analisarmos a cidadania das crianças exclusivamente através das lentes dos direitos, perdemos muito do que é importante em sua experiência e para o seu reconhecimento como cidadáos. Antes, sim, devemos buscar o reconhecimento do exercício de cidadania onde ela ocorre, constituída como de fato (LISTER, 2007).

A literatura sobre cidadania só recentemente e de forma muito superficial começou a abordar o que significa a cidadania para as crianças no aqui e agora. Há uma tendência de "ignorar completamente as crianças, implicitamente igualando a cidadania com adultez, ou retratando as crianças como cidadãos do futuro: variavelmente descrita criticamente como 'cidadão-em-espera', 'cidadão aprendiz' ou 'aprendiz de cidadão'" (LISTER, 2007, p. 696, tradução nossa). A defesa é a da cidadania como uma prática que expressa a própria ação humana. A ligação entre concepçôes de cidadania e a prática de participação ativa é a chave para a noção de ação humana, que prevê, como um conjunto de direitos, objetos de lutas, a cidadania como direito que permite às pessoas agirem.

Considerando que, "no que se refere ao status de sujeito das crianças, seus direitos de participação são bem mais relevantes” (QVORTRUP, 2010, p. 780), como podemos traçar um caminho de pensamento, estudo, reflexão e compromisso com a efetiva instauração de práticas pedagógicas nas creches e pré-escolas que concretizem as vivências dos direitos das crianças?

Para o êxito do anúncio de um espaço educativo democrático é necessária a efetiva participação de todos os sujeitos da relação pedagógica: profissionais, familiares e crianças, para que creches e pré-escolas possam ser entendidos, antes de tudo, como "fóruns, espaços ou locais para a prática ética e política" (DAHLBERG; MOSS, 2005, 
p. 1-2, tradução nossa), "locais de prática política - e especificamente de prática política democrática” (MOSS, 2009, p. 418).

Um dos primeiros passos para que essa prática democrática se instaure na educação infantil é a opção por este direcionamento, que se constrói com intencionalidade (MOSS, 2009). Desse modo, é fundamental que as pré-escolas e creches, assim como os sistemas que as apoiam, pensem e reflitam o que a democracia pode significar nos contextos de educação infantil (DAHLBERG; MOSS, 2005; MOSS, 2009; BAE, 2009), evitando visões irrefletidas sobre ela.

É necessário compreender a democracia como um fenômeno processual sendo criado pelos participantes, como algo vivido, corroborando, desse modo, a ideia de que a participação não é dada, mas sim um processo que envolve interação, expressão de ideias, pensamentos, opinióes, sentimentos, escolhas, negociaçóes; enfim, é praticada na relação social.

Os modelos de participação e cidadania frequentemente negligenciam as especificidades das crianças e são projetados de forma unilateral por adultos.

A linguagem e as práticas das políticas e da formulação de políticas tendem a ser alienantes para crianças, e as formas preferidas das crianças de expressar opiniōes precisam ser melhor compreendidas e traduzidas para os processos políticos. Tais compreensóes são importantes tentativas de fomentar a participação parcial ou mal fomentada, que podem ter fortes efeitos negativos, levando à insatisfaçáo e à exclusão social e podem agravar as desvantagens das pessoas jovens. (COCKBURN, 2010, p. 309, tradução nossa).

Abordagens alternativas à participação na esfera pública são necessárias para se acomodar uma grande diversidade de vozes infantis. Michael Wyness (2009) tem se dedicado à temática e alerta para a necessidade de sermos cuidadosos ao incluir as estruturas formais eleitorais com as crianças, pois é improvável que possam acolher a diversidade de vozes infantis. Esse modelo gera relaçôes hierárquicas e tende a legitimar uma relação de poder entre os eleitos e os eleitores, podendo silenciar grupos já marginalizados dentro da sociedade. A opiniāo das crianças menores nos espaços educativos pode ser interpretada como uma força, especialmente, se estivermos à procura da voz das crianças, para tanto, temos de explorar alternativas aos modos de representação e participação formais.

Apresenta-se a importância de pensarmos caminhos para a participaçáo das crianças pequenas ancorados em perspectivas que busquem respostas para a sociedade 
complexa em que vivemos, sendo, então, importante reconhecer diferentes formas de participação, tanto em ambientes formais quanto informais, com base nos padróes culturais e nas práticas das crianças em seu cotidiano, envolvendo-as de acordo com questôes que lhes são significativas (WYNESS, 2009; COCKBURN, 2010, JANS, 2004).

A possibilidade de se expressar e de ser ouvido desempenha um papel crucial para as crianças. A proposta, nesse sentido, é o estabelecimento do diálogo, o qual requer sensibilidade, astúcia, perspicácia e conhecimento para que sejam travados e entendidos os diversos canais de comunicaçáo, com atenção ao compartilhamento do poder, reconhecendo a interdependência que une crianças e adultos para a construção do bem comum, promovendo democracia e cidadania. Assim,

A implementaçáo do Artigo 12 requer o reconhecimento e o respeito pelas formas não verbais de comunicação, como a brincadeira, a linguagem corporal, expressão facial ou desenhos e pinturas, através dos quais as crianças pequenas fazem escolhas, expressam preferências e demonstram seus entendimentos do seu ambiente. (LANSDOWN, 2010, p. 12, tradução nossa).

As formas de apreender e expressar o mundo estão guiadas por todas as dimensôes do humano, sem que apresentem o privilégio de alguns dos meios consagrados em nossa sociedade completamente desenvolvidos - fala e escrita. Os ricos e diversos modos comunicacionais pelos quais as crianças se expressam revelam suas formas de serem e estarem. Nelas não recaem distanciamentos e divisôes das dicotomias instauradas; mente e corpo, razão e emoção são pares híbridos, que se expóem em presença nas formas como conduzem a tessitura de suas ordens sociais com o grupo de pares e com os adultos.

Destaca-se, em seus modos próprios de participar, a sua pertença geracional, que, embora cruzada com as outras categorias sociais, colocam acento na sua forma de fazê-lo, na sua dimensão corporal, afetiva, humorística, lúdica, em suas culturas de pares. Ao exercitarem sua autonomia, expressarem seus pontos de vista e negociarem a estruturação de seus mundos de vida, as crianças visibilizam sua capacidade e interesse em participar. Esse é um importante princípio a ser considerado na execução das práticas pedagógicas. 


\section{Para finalizar}

As ideias aqui apresentadas buscam fomentar a participação das crianças na vida pública do espaço educativo e seu exercício de cidadania. Propóe o desafio da construção de uma ideia e prática de cidadania nas creches e pré-escolas na qual as diferenças sejam respeitadas, travem negociaçóes no encontro público num caminho para que se consolide um espaço justo e solidário. A participação ativa das crianças é questáo fundamental para o diálogo e para o confronto com a diferença, considerada como importante elemento constituidor desses espaços públicos de educação.

Faz-se necessário desconstruir os pressupostos universais aplicados à cidadania e que contribuem para a geração das exclusóes. Nos contextos de educação infantil - em que a sistematicidade com que cotidianamente os encontros se forjam, entre as diferentes meninas e meninos, com capitais sociais, culturais, econômicos e físicos diversos -, torna-se fulcral aprofundar, refletir e a explicitar os aspectos norteadores da sua construção enquanto espaço educativo democrático.

A contribuição dos Estudos da Criança que as compreendem como atores sociais consiste em impulsionar o reconhecimento delas como cidadãos ativos, forjando um olhar que se contrapóe ao entendimento das crianças como objetos passivos das políticas e práticas adultas e cuja cidadania é vista como um potencial e um estatuto a ser alcançado no futuro; defende, ainda, a participação e a contribuição das crianças para o fortalecimento da democracia.

O destaque aqui é a defesa da construção da experiência educativa pelos próprios atores sociais. Compreendendo que é pela prática da participaçáo democrática que se constrói a democracia. Compreenda-se, ainda, como importante fator de aprendizagem e vivência da cidadania, que as açóes das crianças tenham valor, que sua presença e participação tenham sentido, que construam seu sentimento de pertença. A defesa da participação infantil afirma a competência e a voz das crianças para, efetivamente, influenciar seus mundos sociais e culturais, sendo-lhes permitido opinar e participar na sua organização.

É imprescindível o desenvolvimento de abordagens adequadas a uma cultura de comunicação que comece a partir da posição da criança, a fim de que possamos construir práticas participativas, estabelecidas no paradigma da ausculta, da escuta e do diálogo por meio das diferentes linguagens, implicadas na comunicaçấo humana. Importa, sobremaneira, construir uma ética discursiva, em que a comunicação se dá por todas as dimensôes humanas.

Uma educação infantil que garanta a cidadania às crianças requer propostas pedagógicas que as reconheçam como sujeitos que se expressam sobre o mundo de 
maneira peculiar, na interação com os elementos da natureza e da cultura, com outras crianças e adultos. Temos de estar atentos aos modos como as crianças se exprimem, considerando todas as formas comunicacionais que utilizam para fazê-lo.

O ponto de vista das crianças deve ser levado em conta, permitindo influenciar as decisões nos assuntos que as afetam, num exercício de poder de decisão compartilhado intergeracionalmente, em que adultos e crianças vivem sua cidadania.

\section{REFERÊNCIAS}

ARAÚJO, Helena. Cidadania na sua polifonia: debates nos estudos de educação feministas. Educação, Sociedade \& Culturas, Porto, n. 25, p. 83-116, 2007.

BAE, Berit. Children's right to participate: challenges in everyday interactions. European Early Childhood Education Research Journal, Birmingham, v. 17, n. 3, p. 391-406, 2009.

BRASIL. Constituição da República Federativa do Brasil, Brasília, DF, 5 out. 1988. BRASIL, Lei n ${ }^{\circ}$ 8.069, de 13 de julho de 1990. Dispóe sobre o Estatuto da Criança e do Adolescente e dá outras providências. Diário Oficial da União, 16 jul. 1990. COCKBURN, Tom. Children and citizenship in Britain: a case for a socially interdependent model of citizenship. Childhood, v. 5, n. 1, p. 99-117, 1998.

COCKBURN, Tom. Children and deliberative democracy in England. In: PERCYSMITH, Barry; THOMAS, Nigel. A handbook of children and young people's participation: perspectives from theory and practice. London: Routledge, 2010. p. 306-317.

DAHLBERG, Gunilla; MOSS, Peter. Ethics and politics in early childhood education. London: Routledge Falmer, 2005.

FERREIRA, Manuela. “- Ela é nossa prisioneira!” Questôes teóricas, epistemológicas e ético-metodológicas a propósito dos processos de obtenção da permissão das crianças pequenas numa pesquisa etnográfica. Revista Reflexão e Ação, Santa Cruz do Sul, v.18, n. 2, p. 151-182, jul./dez. 2010.

HILL, Malcolm et al. Moving the Participation Agenda Forward. Children \& Society, v. 18, p. 77-96, 2004.

JANS, Marc. Children as citizens: towards a contemporary notion of child participation. Childhood, v. 11, n. 1, p. 27-44, 2004. 
KRAMER. Sônia. Infância, cultura contemporânea e educação contra a barbárie. In: BAZÍLIO, Luiz Cavalieri; KRAMER, Sônia. Infância, educação e direitos humanos. São Paulo: Cortez, 2003. p. 54-70.

LANSDOWN, Gerison. ¿Me haces caso? El derecho de los niños pequeños a participar en las decisiones que los afectan. Cuadernos sobre Desarrollo Infantil Temprano, Haya n. 36, 2005.

LANSDOWN, Gerison. The realisation of children's participation rights. In: PERCY-SMITH, Barry; THOMAS, Nigel. A handbook of children and young people's participation: perspectives from theory and practice. London: Routledge, 2010. p. 11-23.

LISTER, Ruth. Why citizenship: where, when and how children? Theoretical Inquiries in Law, v. 8, n. 2, p.693-718, 2007.

MOSS, Peter. Introduzindo a política na creche: a educação infantil como prática democrática. Psicologia USP, Sáo Paulo, v. 20, n. 3, p. 417- 436, jul./set. 2009.

PELBART, Peter. A Nau do Tempo Rei: 7 Ensaios sobre o tempo da loucura. Rio de Janeiro: Imago, 1993.

PERCY-SMITH, Barry; THOMAS, Nigel. A handbook of children and young people's participation. Perspectives from theory and practice. London: Routledge, 2010.

QVORTRUP, Jens. Infância e política. Cadernos de Pesquisa, São Paulo, v. 40, n.141, p. 777-792, set./dez. 2010.

SANTOS, Boaventura de Sousa. Palavras de abertura. Revista Critica de Ciências Sociais, Coimbra , n. 52, p.7-11, 1999.

SARMENTO, Manuel. Lógicas de acção nas escolas. Braga: Instituto de Inovação Educacional, 2000.

SOARES, Natália. Os Direitos das Crianças nas encruzilhadas da protecção e da participação. Revista Zero a Seis, Florianópolis, SC, v. 7, n. 12, jul./dez. 2005.

Disponível em:

<https://periodicos.ufsc.br/index.php/zeroseis/article/download/2100/1780>.

UNICEF. Fundo das Nações Unidas para a Infância. Convenção sobre os Direitos da Criança. Nova York, 20 nov. 1989. Disponível em:

<http://www.unicef.org/brazil/pt/resources_10120.htm>. 
UNITED NATIONS. Office of the High Commissioner for Human Rights General. General Comment no. 7 (2005): implementing child rights in early childhood. Geneva, 20 sep. 2006. Disponível em:

$<$ www2.ohchr.org/english/bodies/crc/docs/advanceversions/generalcomment $7 \mathrm{rev1.p}$ $\mathrm{df}>$.

WYNESS, Michael. Children representing children participation and the problem of diversity in UK youth councils. Childhood, v. 16, n. 4, p. 535-552, 2009.

YOUNG, Iris. Intersecting voices: dilemas of gender, political philosophy, and policy. Princeton: Princeton University Press, 1997. 


\section{The complexity of children participation in early childhood education}

\section{Abstract}

The present study supports the inclusion and participation of children in daycare and preschool for the production of spaces of democratic education that counter social exclusion and contribute in the production and consolidation of a society of social rights claim. Children's participation remains largely to be achieved, a challenge that must be faced in its contradictions, dilemmas and theoretical, social and political paradoxes. By deepening this theme we understand its theoretical complexity, and it is on this complexity this text dwells. The discussion of children's participation for democratic education intersects with a number of important concepts that need to be investigated, understood and connected, so we can rely on generational contributions in the effectiveness of education advocated here, that win adult-focused models and not may waive the theoretical production of inclusive approaches. Children as subjects of knowledge and producers of meaning have "voice", the forms of communication and relationship they use to express themselves are legitimate and, in so doing, they contribute to the renewal and reproduction of the contexts in which they participate when there is anyone interested to hear their voices. It is important to recognize the different forms of participation of young children based on their cultural patterns and their daily practices, on issues that are significant to them and concern them.

Keywords: Childhood. Childhood education. Children Rights.

\section{La complejidad de Ia participación de los niños en la educación de la primera infancia}

\section{Resumen}

El presente estudio defiende la inclusión y la participación de los niños en los jardines maternales y en el preescolar para la producción de espacios de educación democrática que contrarresten la exclusión social y contribuyan a la producción y la consolidación de una sociedad que respete los derechos sociales. La participación de los niños aún sigue siendo un desafío que hay que afrontar en sus contradicciones, dilemas y paradojas teóricas, sociales y políticos. Al profundizar el tema comprendemos su complejidad teórica y es sobre esta complejidad que este texto tratará. Para la discusión sobre la participación de los niños para la educación democrática es necesaria una serie de conceptos importantes que deben ser investigados, entendidos para que podamos generar contribuciones generacionales en la educación que aquí se defiende, que puedan superar modelos adultocêntricos y para esto, no podrá renunciar a la producción teórica de enfoques inclusivos. Los niños como sujetos de conocimiento y productores de sentido tienen "voz", son legítimas las formas de la comunicación y de relación que utilizan para expresarse y, de este modo, contribuyen en la renovación y la reproducción de los contextos en los que participan cuando hay alguien interesado para escuchar sus voces. Es importante reconocer las diferentes formas de participación de los niños en función de sus patrones culturales, sus prácticas cotidianas y en temas que son importantes para ellos.

Palabras claves: Infancia. Educación Infantil. Derechos de los niños. 
Kátia Adair Agostinho

E-mail: katia.agostinho@ufsc.br

Recebido em: 23/2/2014

Aprovado em: 8/8/2014 